\title{
Pattern of utilization, disease presentation, and medication prescribing and dispensing at 51 primary healthcare centers during the Hajj mass gathering
}

Saber Yezli ${ }^{1 *}$, Yara Yassin ${ }^{1}$, Abdulaziz Mushi ${ }^{1}$, Yasir Almuzaini ${ }^{1}$ and Anas Khan ${ }^{1,2}$

\begin{abstract}
Background: The majority of pilgrims seeking healthcare during Hajj are seen at primary healthcare centers (PHCCs). Data on the utilization of these facilities during Hajj can aid in directing optimal health services delivery and allocation of resources during the pilgrimage.

Method: We investigated the pattern of disease presentation, caseload, and medication prescribing and dispensing at 51 PHCCs during the 2019 Hajj. Data on patients' demographics, diagnoses, and prescribed medications were retrieved from each PHCC's electronic records and analyzed. Data were also used to calculate six of the World Health Organization (WHO) indicators for drug use at these facilities.

Results: Data were captured for 99,367 patients who were mostly Hajj pilgrims (95.4\%), male (69.1\%) from the Eastern Mediterranean (60.8\%) and had a mean age of 46.6 years $(S D=14.9)$. Most patients (85.2\%) were seen in Mina and towards the end of Hajj. The majority of patients (96.0\%) had a single diagnosis; most commonly, respiratory (45.0\%), musculoskeletal (17.2\%), and skin (10.5\%) diseases. Patients were prescribed 223,964 medications, mostly analgesics (25.1\%), antibacterials for systemic use (16.5\%), anti-inflammatory and antirheumatic products (16.4\%), and cough and cold preparations (11.9\%). On average, $2.25(\mathrm{SD}=0.94)$ medications were prescribed per consultation, with low (1.3\%) prevalence of polypharmacy. An antibiotic and an injectable were prescribed in 43.6 and $2.67 \%$ of patient encounters, respectively. Most (92.7\%) of the prescribed drugs were actually dispensed, in an average time of $8.06 \mathrm{~min}(\mathrm{SD}=41.4)$. All PHCCs had a copy of the essential drugs list available, on which all the prescribed drugs appeared.
\end{abstract}

Conclusion: Respiratory illnesses are the main reason for PHCCs visits during Hajj, and analgesics and antibiotics are the most common medications prescribed to pilgrims. Our results, including the calculated WHO drug use indicators, contribute to evidence-based optimization of primary healthcare services during Hajj.

Keywords: Primary care, WHO drug use indicators, Diagnosis, Health service utilization, Prescribing pattern, Disease

*Correspondence: saber.yezli@gmail.com

${ }^{1}$ The Global Centre for Mass Gatherings Medicine, Ministry of Health, Riyadh, Saudi Arabia

Full list of author information is available at the end of the article

\section{Introduction}

The Hajj pilgrimage to Makkah, Kingdom of Saudi Arabia (KSA), is one of the five pillars of Islam and is a religious duty for every Muslim who is physically and financially able to perform it [1]. Hajj is undertaken over a few specific days during the 12th month (DulHija) of the Islamic calendar, although most pilgrims spend longer times in 
Makkah and/or visiting the holy city of Medina. During the Hajj ritual days, pilgrims move to the holy site of Mina where they spend a few days, including 1 day (9th DulHija) in the desert plain of Arafat and a short stay at Muzdalifah area [1]. Each year, 2-3 million pilgrims from around the world perform the physically demanding Hajj rituals in crowded conditions, often outdoors [1, 2]. As such, the mass gathering presents a number of public health risks, including the transmission of infectious diseases, exacerbation of underlying health conditions, accidents and injuries, as well as environmental-related health conditions [3].

Saudi authorities use a well-coordinated and inter-sectoral approach to orchestrate the public health planning and management of Hajj, which includes addressing the increased demand for health services during the event. Free healthcare is provided for Hajj pilgrims through numerous permanent and seasonal (only operational during the Hajj season) hospitals and primary healthcare centers (PHCCs) in Makkah and Medina. In 2018, 21 permanent and eight seasonal hospitals were available, in addition to 33 permanent and 106 seasonal PHCCs [2]. Of the latter, 93 were located in the holy sites of Mina, Arafat and Muzdalifah. Pilgrims of certain countries may also access healthcare through their own Hajj medical missions [4].

Data on the pattern of diseases presentation and medication use at healthcare facilities during Hajj can assist public health planning for the event and direct optimal resources allocation and services delivery for pilgrims. Such data can also highlight gaps in the health system that need addressing for the provision of better healthcare in general. Several studies reported on the pattern of diseases and medication use among pilgrims attending hospitals during Hajj [5-8]. However, few reported on pilgrims attending PHCCs $[9,10]$, which represent the majority of those seeing healthcare during the event. For instance, Saudi Ministry of Health statistics indicates that during the 2018 Hajj season, 586,587 pilgrims visited PHCCs compared to 53,038 and 98,163 who visited hospitals' ERs and outpatient departments (OPDs), respectively [2]. The above studies were conducted over a decade ago and were focused on PHCCs located in Mina. In addition, medication use and prescribing patters in PHCCs during Hajj were not previously investigated using the measurable World Health Organization (WHO) drug use indicators for health facilities [11].

This study aims to determine the pattern of disease presentation, caseload, and medication prescribing and dispensing at seasonal PHCCs in Mina, Arafat, and Muzdalifah, during Hajj. This is to provide an evidence base to direct optimal health services delivery and allocation of resources during the pilgrimage.

\section{Methods}

\section{Study design and setting}

We conducted a retrospective, descriptive cross-sectional study during the 2019 Hajj. The study period was from the 7th-13th DulHija $1440 \mathrm{H}$ corresponding to 8th-14th August 2019. Data were obtained from 51 PHCCs located in the holy Hajj sites of Mina, Arafat and Muzdalifah, in Makkah, KSA. These represent 55\% of PHCCs in these holy sites.

\section{Data collection and management}

Data were retrieved from the PHCCs' electronic health records and included demographic information of the patients (age, gender, nationality, residency, and Hajj status), diagnoses, and prescribed medications (name, dosage, and dates and times of prescribing and dispensing). Patients' diagnoses were grouped and reported as chapters of the 10th revision of the International Classification of Diseases (ICD-10). We assigned the medications' therapeutic classes based on the Anatomical Therapeutic Chemical (ATC) classification system of the WHO Collaborating Center on Drug Statistics Methodology (https://www.whocc.no/). Polypharmacy and excessive polypharmacy were defined as prescribing $\geq 5$ medications and $\geq 10$ medications per encounter, respectively [12].

\section{Data analysis}

Descriptive statistics (e.g., mean, standard deviation (SD), frequencies, percentages) were computed for variables as appropriate. Medications prescribing patterns at the PHCCs were evaluated using the WHO core drug use indicators for health facilities [11]. Based on the available data, six indicators were calculated: four prescribing indicators (average number of drugs per encounter, percentage of encounters with an antibiotic or an injection prescribed and percentage of drugs prescribed from essential drugs list or formulary); one patient care indicator (percentage of drugs actually dispensed) and one health facility indicator (availability of a copy of essential drugs list or formulary). The average time from medication prescribing to dispensing was also calculated as a proxy to a second WHO patient care indicator; average dispensing time, as reported previously [5]. Data were analyzed using SPSS 22.0 (SPSS Inc., Chicago, USA) statistical package.

\section{Results}

\section{Patients' characteristics}

Data were captured for 99,367 patients who attended 51 PHCCs in the holy sites of Mina, Arafat and Muzdalifah during the study period (Table 1). Patients originated from 186 countries and territories worldwide, 
Table 1 Demographic characteristics of patients attending the 51 seasonal primary healthcare centers in the holy sites during the 2019 Hajj

\begin{tabular}{|c|c|c|}
\hline Variable & $\mathrm{n}$ & $\%$ \\
\hline Gender & 99,293 & \\
\hline Male & 68,587 & 69.1 \\
\hline Female & 30,706 & 30.9 \\
\hline Age (Years) & 72,913 & \\
\hline$\leq 19$ & 2249 & 3.1 \\
\hline $20-34$ & 13,079 & 17.9 \\
\hline $35-49$ & 23,800 & 32.6 \\
\hline $50-64$ & 25,731 & 35.3 \\
\hline$\geq 65$ & 8054 & 11.0 \\
\hline Residency & 99,367 & \\
\hline Visitor & 87,146 & 87.7 \\
\hline Saudi resident & 2362 & 2.4 \\
\hline Saudi national & 9608 & 9.7 \\
\hline Unknown & 251 & 0.2 \\
\hline Hajj status & 99,367 & \\
\hline Hajj pilgrim & 94,756 & 95.4 \\
\hline Non-Pilgrim & 4611 & 4.6 \\
\hline Nationality ${ }^{\mathrm{a}}$ & 99,367 & \\
\hline Africa & 21,180 & 21.3 \\
\hline Americas & 1567 & 1.6 \\
\hline Eastern Mediterranean Region & 60,394 & 60.8 \\
\hline Europe & 3580 & 3.6 \\
\hline Other & 53 & 0.1 \\
\hline South-East Asia & 10,812 & 10.9 \\
\hline Western Pacific Region & 1781 & 1.8 \\
\hline Facility location & 99,367 & \\
\hline Arafat (20 PHCCs) & 9102 & 9.2 \\
\hline Mina (25 PHCCs) & 84,687 & 85.2 \\
\hline Muzdalifah (6 PHCCs) & 5578 & 5.6 \\
\hline
\end{tabular}

PHCC primary healthcare center

${ }^{\text {a }}$ According to the World Health Organization (WHO) regions

mainly from the Eastern Mediterranean (60.8\%), Africa (21.3\%) and South-East Asia (10.9\%) regions. The most represented countries were Egypt (18.8\%), Nigeria (10.9\%), Pakistan (9.1\%), Saudi Arabia (8.1\%) and India (6.3\%). Most patients were Hajj pilgrims (95.4\%), non-KSA residents/nationals (87.7\%) and male (69.1\%). Age was reported for $73.3 \%$ of patients with a mean age of 46.6 years ( $\mathrm{SD}=14.9$, range $0-106$ years). Most patients $(85.2 \%)$ were seen at the 25 PHCCs located in Mina (Table 1). Pilgrims attended the PHCCs from the 8th-14th August (7th-13th DulHija) with the highest attendance from 11th-13th August (10th-12th DulHijja) (Fig. 1). The largest caseload at Arafat PHCCs was on the 10th August (9th DulHija).

\section{Pattern of diseases}

During the study period, 78,105 diagnoses were made, ten of which accounted for over $99 \%$ of all diagnoses (Table 2). Diseases of the respiratory system were the most commonly reported (45.0\%); of which $72.7 \%$ were related to upper respiratory tract infections (URIs). Diseases of the musculoskeletal system and connective tissue accounted for $17.2 \%$ of diagnoses (mainly muscle strain (33.6\%), joint and lower back pain (29.0\%) and, arthritis $(16.8 \%))$. Diseases of the skin and subcutaneous tissue represented $10.5 \%$ of diagnoses (mainly dermatitis $(34.6 \%)$ ). Few patients (4.0\%) had multiple diagnoses. In general, the pattern of disease among pilgrims was similar across locations, although some differences were noted (Table 2). For instance, diseases of the skin and subcutaneous tissue were the second most common diagnoses in Muzdalifah PHCCs, while being ranked third in Mina and Arafat PHCCs.

\section{Medications}

Patients were prescribed 223,964 medications, mostly at the Mina PHCCs (86.7\%) (Table 3). The most prescribed classes of medications were analgesics (25.1\%), antibacterials for systemic use (16.5\%), anti-inflammatory and antirheumatic products (16.4\%), and cough and cold preparations (11.9\%). Only $1.3 \%$ of the medications were injectable, and $20.8 \%$ were antibiotics. Most of the latter were broad-spectrum, in particular amoxicillin (59.6\%) and azithromycin (15.8\%). In general, the prescribed drugs represented 221 different medications, of which 20 accounted for $91.2 \%$ of all medications prescribed during the study period (Table 4). Of these 20 medications, 65.0 and $30.0 \%$ were oral and topical medications, respectively, and none were injectable.

\section{WHO indicators for drug use in PHCCs}

During the study period, there were 99,444 patient encounters at the $51 \mathrm{PHCCs}$ where medications were prescribed (Table 3). WHO drug use indicators that were possible to calculate from the available data are presented in Table 5. An average of $2.25(\mathrm{SD}=0.94)$ medications were prescribed to patients per consultation. This value was lowest in Muzdalifah PHCCs (1.99; SD =0.88) and highest in Mina PHCCs (2.29; SD =0.94). In most encounters, 2 or 3 medications were prescribed (Fig. 2). The proportions of encounters with 1, 2, 3, and 4 medications prescribed were $22.8,39.5,29.1$, and $7.3 \%$ respectively. Polypharmacy was rare, observed in $1.3 \%$ of the encounters, while excessive polypharmacy was recorded in only one encounter $(0.001 \%)$.

An antibiotic and an injectable were prescribed in 43.6 and $2.67 \%$ of patient encounters respectively. Mina 


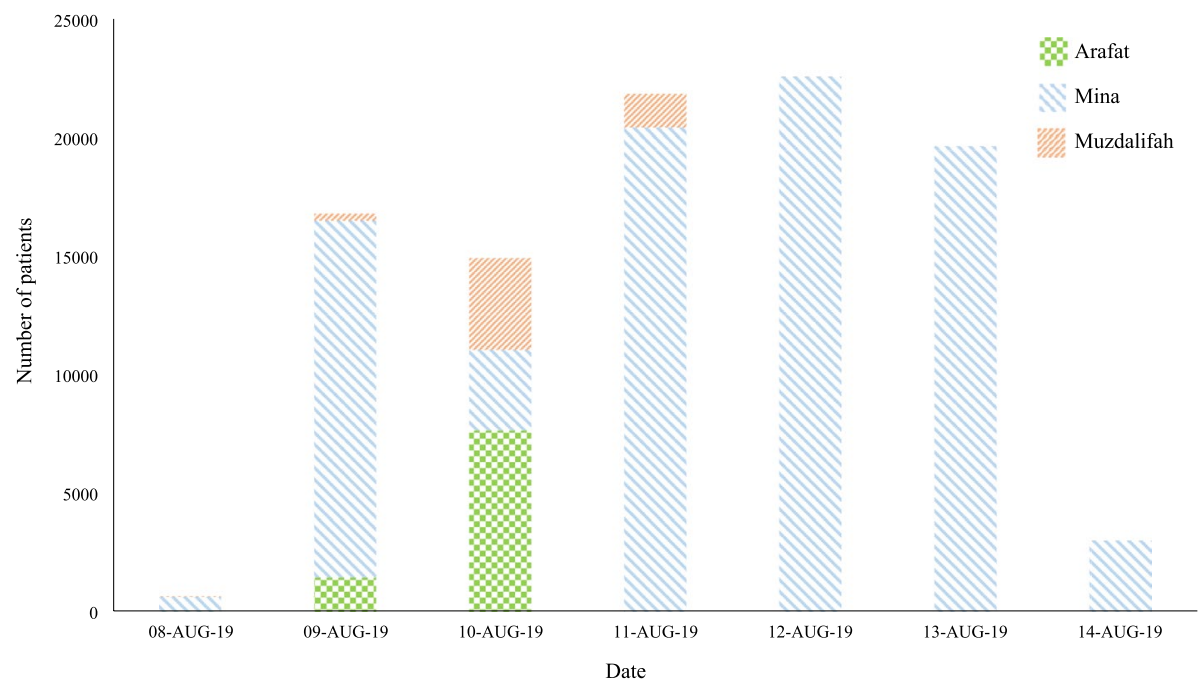

Fig. 1 Number of patients attending 51 seasonal primary healthcare centers in the holy sites during the 2019 Hajj

Table 2 The most common diagnosis among patients attending the 51 seasonal primary healthcare centers in the holy sites during the 2019 Hajj

\begin{tabular}{|c|c|c|c|c|}
\hline \multirow[t]{2}{*}{ Diagnosis according to ICD-10 classification } & \multicolumn{4}{|l|}{$\%$} \\
\hline & All $(n=78,105)$ & $\begin{array}{l}\text { Mina } \\
(n=65,731)\end{array}$ & $\begin{array}{l}\text { Arafat } \\
(n=7791)\end{array}$ & $\begin{array}{l}\text { Muzdalifah } \\
(n=4583)\end{array}$ \\
\hline Diseases of the respiratory system & 45.0 & 46.6 & 39.2 & 31.4 \\
\hline Diseases of the musculoskeletal system and connective tissue & 17.2 & 17.5 & 12.9 & 20.0 \\
\hline Diseases of the skin and subcutaneous tissue & 10.5 & 9.4 & 12.7 & 23.2 \\
\hline $\begin{array}{l}\text { Symptoms, signs and abnormal clinical and laboratory findings, not } \\
\text { elsewhere classified }\end{array}$ & 8.3 & 7.7 & 12.5 & 8.8 \\
\hline Diseases of the digestive system & 7.9 & 7.8 & 9.4 & 7.3 \\
\hline Injury, poisoning and certain other consequences of external causes & 4.4 & 4.4 & 5.0 & 2.9 \\
\hline Endocrine, nutritional and metabolic diseases & 1.7 & 1.6 & 2.6 & 1.2 \\
\hline Diseases of the eye and adnexa & 1.6 & 1.6 & 1.8 & 1.9 \\
\hline Diseases of the circulatory system & 1.5 & 1.5 & 1.9 & 1.0 \\
\hline Diseases of the genitourinary system & 1.1 & 1.1 & 0.8 & 1.8 \\
\hline
\end{tabular}

ICD-10 10th revision of the International Classification of Diseases

Table 3 Distribution of patients, encounters and prescribed medications in the 51 seasonal primary healthcare centers in the holy sites during the 2019 Hajj

\begin{tabular}{|c|c|c|c|c|c|c|}
\hline \multirow[t]{2}{*}{$\operatorname{PHCC}(n)$} & \multicolumn{2}{|c|}{ Patients } & \multicolumn{2}{|c|}{ Encounters } & \multicolumn{2}{|c|}{ Medications } \\
\hline & $\mathbf{n}$ & $\%$ & $\mathbf{n}$ & $\%$ & $\mathbf{n}$ & $\%$ \\
\hline Mina (25) & 84,687 & 85.2 & 84,754 & 85.2 & 194,305 & 86.7 \\
\hline Arafat (20) & 9102 & 9.2 & 9110 & 9.2 & 18,549 & 8.3 \\
\hline Muzdalifah (6) & 5578 & 5.6 & 5580 & 5.6 & 11,110 & 5 \\
\hline Total & 99,367 & 100 & 99,444 & 100 & 223,964 & 100 \\
\hline
\end{tabular}

PHCC primary healthcare center 
Table 4 The 20 most common medications prescribed to patients attending the 51 seasonal primary healthcare centers in the holy sites during the 2019 Hajj

\begin{tabular}{|c|c|c|c|c|c|c|}
\hline Rank & Medication name & Form & ATC & ATC classification & $\mathbf{n}$ & $\%$ \\
\hline 1 & Paracetamol & Oral & N02 & Analgesics & 51,257 & 22.9 \\
\hline 2 & Amoxicillin Trihydrate & Oral & J01 & Antibacterials for systemic use & 26,596 & 11.9 \\
\hline 3 & Ibuprofen 400 mg Tablet & Oral & M01 & Antiinflammatory and antirheumatic products & 19,794 & 8.8 \\
\hline 4 & Dextromethorphan Hydrobromide & Oral & R05 & Cough and cold preparations & 17,331 & 7.7 \\
\hline 5 & Chlorpheniramine Maleate & Oral & R06 & Antihistamines for systemic use & 15,177 & 6.8 \\
\hline 6 & Diclofenac & Oral/Topical & M01 & Antiinflammatory and antirheumatic products & 13,785 & 6.2 \\
\hline 7 & Azithromycin & Oral & J01 & Antibacterials for systemic use & 7132 & 3.2 \\
\hline 8 & $\begin{array}{l}\text { Diphenhydramine, Ammonium Chloride \& Sodium } \\
\text { Citrate }\end{array}$ & Oral & R05 & Cough and cold preparations & 6984 & 3.1 \\
\hline 9 & Aluminum-Magnesium Hydroxide & Oral & $\mathrm{A} 02$ & Drugs for acid related disorders & 5893 & 2.6 \\
\hline 10 & Naphazoline Hydrochloride \& Chlorpheniramine & Nasal & R01 & Nasal preparations & 5374 & 2.4 \\
\hline 11 & Hyoscine Butylbromide & Oral & $\mathrm{A} 03$ & Drugs for functional gastrointestinal disorders & 5114 & 2.3 \\
\hline 12 & Hydrocortisone & Topical & D07 & Corticosteroids, dermatological preparations & 4951 & 2.2 \\
\hline 13 & Paraffin & Topical & D02 & Emollients and protectives & 4490 & 2.0 \\
\hline 14 & Magnesium Silicate & Oral & $\mathrm{A} 02$ & Drugs for acid related disorders & 3876 & 1.7 \\
\hline 15 & Metronidazole & Oral & P01 & Antiprotozoals & 3200 & 1.4 \\
\hline 16 & Silver Sulfadiazine & Topical & D06 & $\begin{array}{l}\text { Antibiotics and chemotherapeutics for dermatologi- } \\
\text { cal use }\end{array}$ & 3068 & 1.4 \\
\hline 17 & Salbutamol & Inhalation & P03 & Drugs for obstructive airway diseases & 3013 & 1.3 \\
\hline 18 & Fusidic Acid & Topical & D06 & $\begin{array}{l}\text { Antibiotics and chemotherapeutics for dermatologi- } \\
\text { cal use }\end{array}$ & 2742 & 1.2 \\
\hline 19 & Calamine & Topical & D02 & Emollients and protectives & 2575 & 1.1 \\
\hline 20 & Rehydration Salt & Oral & $\mathrm{A} 07$ & $\begin{array}{l}\text { Antidiarrheals, intestinal antiinflammatory/antiinfec- } \\
\text { tive agents }\end{array}$ & 1910 & 0.9 \\
\hline
\end{tabular}

ATC Anatomical Therapeutic Chemical

Table 5 WHO core drug use indicators for the 51 seasonal primary healthcare centers in the holy sites during the 2019 Hajj

\begin{tabular}{|c|c|c|c|c|}
\hline \multirow[b]{2}{*}{ Indicator } & \multicolumn{4}{|c|}{ PHCCs location (n) } \\
\hline & Mina (25) & Arafat (20) & Muzdalifah (6) & All (51) \\
\hline \multicolumn{5}{|l|}{ Prescribing indicators } \\
\hline Average number of drugs per encounter ( $\pm \mathrm{SD}$ ) & $2.29(0.94)$ & $2.04(0.93)$ & $1.99(0.88)$ & $2.25(0.94)$ \\
\hline$\%$ of encounters with an antibiotic prescribed & 45.8 & 31.2 & 30.4 & 43.6 \\
\hline$\%$ of encounters with an injection prescribed & 2.52 & 4.41 & 2.04 & 2.67 \\
\hline$\%$ of drugs prescribed from essential drugs list or formulary & 100 & 100 & 100 & 100 \\
\hline \multicolumn{5}{|l|}{ Patient care indicators } \\
\hline$\%$ of drugs actually dispensed & 92.6 & 92.0 & 96.2 & 92.7 \\
\hline Average time ( $\mathrm{min}$ ) between prescribing and dispensing $( \pm \mathrm{SD})^{\mathrm{a}}$ & $7.8(40.8)$ & $10.2(49.5)$ & $8.36(36.8)$ & $8.06(41.4)$ \\
\hline \multicolumn{5}{|l|}{ Health facility indicator } \\
\hline Availability of copy of essential drugs list or formulary & Yes & Yes & Yes & Yes \\
\hline
\end{tabular}

SD standard deviation, $P H C C$ primary healthcare centers

${ }^{\text {a }}$ not a WHO drug use indicator

PHCCs had the highest percentage of encounters where an antibiotic was prescribed (45.8\%), while Arafat PHCCs had the highest percentage of encounters where an injectable was prescribed (4.41\%). In all PHCCs, a copy of the essential drugs list was available, and all the prescribed drugs appeared on that list. Most (92.7\%) of prescribed drugs were actually dispensed at the PHCCs (Table 5). On average, medications were dispensed $8.06 \mathrm{~min}$ $(\mathrm{SD}=41.4)$ from the time they were prescribed for patients. It took slightly longer to dispense medications 


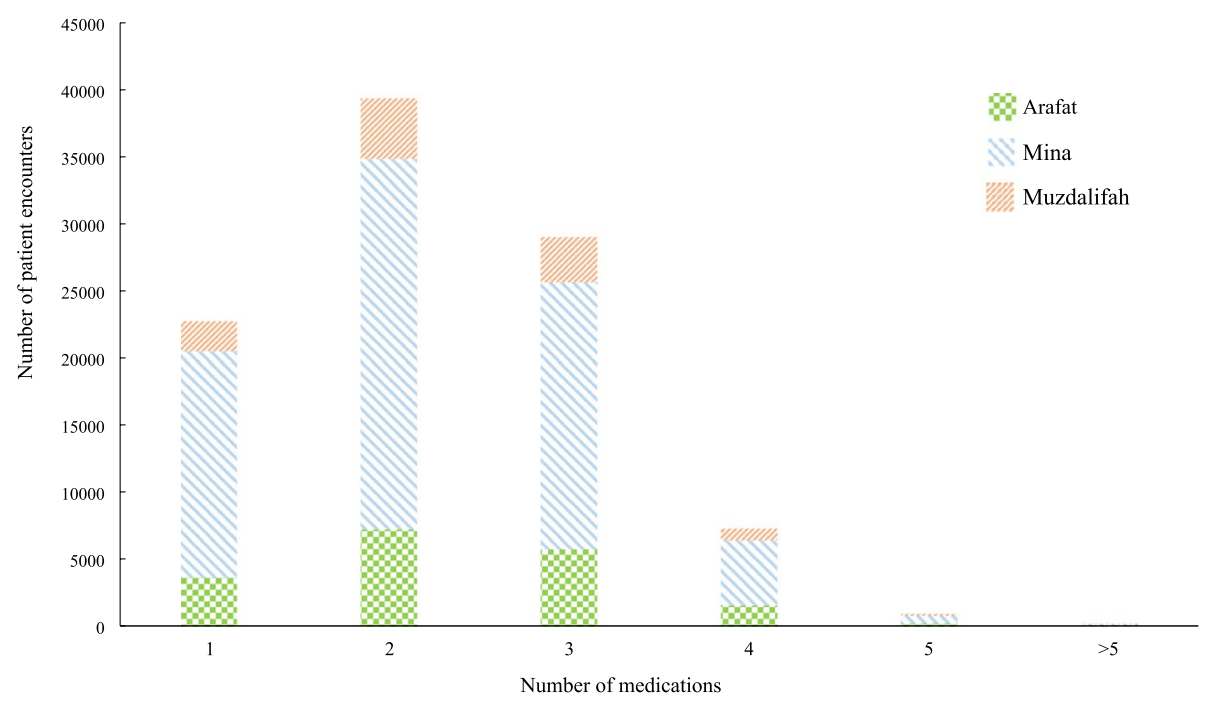

Fig. 2 Number of medication prescribed per patient encounter at the 51 seasonal primary healthcare centers in the holy sites during the 2019 Hajj

in Arafat PHCCs (10.2 min; SD=49.5). Most (91.6\%) of the medications were dispensed within $10 \mathrm{~min}$ of being prescribed, $79.7 \%$ within $5 \mathrm{~min}$, and only $1.5 \%$ were dispensed over $1 \mathrm{~h}$ from the time they were prescribed.

\section{Discussion}

In the current study, nearly 100,000 pilgrims originating from 186 different countries visited PHCCs in the holy sites during a one-week period; a reflection of the large size and international nature of the Hajj. Yet, pilgrims were mainly older males and from Egypt, Nigeria, Pakistan, KSA, and India. These results are similar to what have been reported previously from PHCCs and hospitals' OPDs during Hajj $[5,9,13,14]$. In one study, patients seeking health services during the 2008 Hajj at PHCCs in Mina originated from 82 countries (particularly Egypt (18.9\%), Pakistan (17.5\%), KSA (8.3\%), Nigeria (6.7\%) and India (5.7\%)), $70.7 \%$ were male, and $42.8 \%$ were 45-64years old [9]. Hajj attracts over 2 million pilgrims, a large proportion of which are older males and over half originate from eight countries: Indonesia, Pakistan, India, KSA, Bangladesh, Turkey, Egypt and Nigeria. The demographics of patients attending PHCCs in our study are a reflections of the Hajj population as well as other potential factors, including proximity of PHCCs to pilgrims' camps, knowledge regarding PHCCs location and opening hours and availability of health services in pilgrims' camps [15]. The latter may be a key reason for the comparatively small proportion of pilgrims from Indonesia and Turkey attending PHCCs in our study, which has also been reported elsewhere $[9,15]$.

Similar to previous findings from PHCCs and hospital OPDs during Hajj $[5,9,10,14]$, most patients in our study were seen in Mina facilities and towards the end of the Hajj, post the day of Arafat. As part of the Hajj rituals, pilgrims spent most of the study period in Mina with only a short stay in Arafat and Muzdalifah. In addition, pilgrims are more likely to suffer health issues post the day of Arafat as the physically demanding activities in crowded environments start to take their toll on pilgrims' health. Alzahrani and colleagues [9] reported that the highest caseload of patients attending Mina PHCCs was 2 days after the day of Arafat. During the latter day, Mina PHCCs received the lowest number of patients, which is understandable given that most pilgrims spend the day in the plane of Arafat; hence most PHCC visits occur at Arafat PHCCs, as also seen in our results.

During the study period, most pilgrims had a single diagnosis, with only $4 \%$ having multiple diagnoses. This is comparable to what has been reported from Mina PHCCs during the 2008 Hajj, albeit in that study, the proportion of patients with multiple diagnoses $(20.2 \%)$ was higher than in our study [9]. However, the pattern of disease was similar to what we reported, with respiratory, musculoskeletal, and skin diseases representing the greatest burden [9]. Respiratory diseases, particularly URIs, were very common regardless of the PHCCs' location, as evidenced by other studies of primary healthcare services during Hajj $[4,9,10,13$, 14]. Respiratory tract infections are the leading cause of infectious diseases in Hajj pilgrims, with a prevalence of 50-93\% [16]. Respiratory disease accounted for 49 and $61 \%$ of diagnoses at Mina PHCCs in 1998 and 2008, respectively [9, 10]. The Hajj environment, which includes crowds, adverse weather and cramped 
accommodations, can result in increased rates of respiratory diseases and facilitate their spread among pilgrims.

The physically demanding Hajj activities, including walking long distances, carrying heavy weights and uncomfortable sleeping conditions, often in crowded settings and exposed to the outside environment, can contribute in the development of musculoskeletal and skin ailments. As such, these diseases are common among pilgrims $[17,18]$, including those seeking primary healthcare during the event $[4,9,10,13,14]$. In our study, musculoskeletal and skin diseases accounted for respectively 17.2 and $10.5 \%$ of diagnoses, which is comparable to the 17.6 and $15.0 \%$ reported from Mina PHCCs in the 2008 Hajj [9]. Skin diseases were the second most common diagnoses in Muzdalifah PHCCs, while being ranked third in Mina and Arafat PHCCs. This may be the result of pilgrims spending most of the day of Arafat in the outside environment and exposed to the elements before moving to Muzdalifah. Dermatitis of various etiologies was the most common skin condition (34.6\%), which is in accordance with a previous report which found that dermatitis accounted for $23.6 \%$ of skin diseases among pilgrims in 1998 [17]. Cardiovascular and metabolic diseases, such as diabetes, represented a small proportion of diagnoses, although these conditions are relatively common among pilgrims [19]. This is in line with other reports from PHCCs during Haji $[9,10,14]$. A possible reason for this observation is that not all pilgrims with chronic illnesses seek medical care unless their conditions decorate or they run out of medications [20]. Also, health issues linked to these conditions typically require a higher level of medical care [4, 21]. For example, among Indian pilgrims in 2016, cardiovascular disease represented $4.6 \%$ of primary care morbidity but $27.1 \%$ of tertiary care referrals [4].

The pattern of medications prescribed to patients was consistent with the pattern of diseases and caseload at various PHCCs. The majority of medications were prescribed at Mina PHCCs, with the common classes being analgesics $(25.1 \%)$, antibacterials for systemic use (16.5\%), anti-inflammatory and antirheumatic products (16.4\%), and cough and cold preparations (11.9\%). This is in line with data from both PHCCs and hospitals OPDs during the pilgrimage as well as from Hajj medical mission camps $[4,5,9,13]$. For example, the most frequently prescribed drugs to patients attending 13 PHCCs in Mina in 2008 Hajj were analgesics and antipyretics (79.4\%), followed by antibiotics (53.9\%) and cough syrups (37.1\%) [9]. In another report, anti-inflammatory and antirheumatic products $(22.9 \%)$, analgesics $(22.8 \%)$ and antibacterials for systemic use $(17 \%)$ were the most commonly prescribed medications for hospital outpatients during the 2018 Hajj [5]. Similarly, data from a Makkah hospital OPD during the 2003 Hajj found that the most common medications dispensed were antibiotics (43.3\%), followed by analgesics and antipyretics (25.2\%) [13].

We assessed the drug utilization performance of PHCCs using a number of WHO indicators that covered prescribing, patient care, and health facilities parameters [11]. For the prescribing indicators, the average number of medications per encounter was $2.25(\mathrm{SD}=0.94)$. This is higher than the proposed admissible range of 1.6-1.8 [22], but in line with previous reports from Mina PHCCs (2.35; $\mathrm{SD}=0.97)$, Hajj seasonal hospitals OPDs (2.6; $\mathrm{SD}=1.2)$ and non-Hajj PHCCs in KSA $(2.4 ; \mathrm{SD}=1.2)$ [5, $9,23]$. Most patients $(77.2 \%)$ received multiple therapies, although polypharmacy ( $\geq 5$ medications) was observed in a very small proportion of encounters (1.3\%). Similar to our findings, most patients attending Mina PHCCs during the 2008 Hajj (80.2\%) and outpatients visiting Haji hospitals in 2018 (84.4\%), received multiple medications $[5,9]$. In the latter study, polypharmacy was reported in $4.8 \%$ of encounters [5]. In general, prescribing of multiple medications is common in an older population with multiple morbidities. Given the unique nature of Hajj and the high prevalence of older pilgrims, many with underlying health conditions [19], it is expected that many pilgrims would be on multiple therapies. Yet, the low rate of polypharmacy is reassuring given that the latter is associated with negative outcomes including adverse drug reactions, failure to comply with treatment, mortality, and financial loss [24-26].

In the current study, the percentage of patients' encounters with an antibiotic prescribed was $43.6 \%$, which is higher than the proposed optimal range (20$26.8 \%)[22,27]$. However, the value is consistent with the frequent prescribing and use of antibiotics during the Hajj. Data from PHCCs, hospital OPDs and medical mission camps report that $43.3-53.9 \%$ of pilgrims were prescribed antibiotics $[4,5,9,13]$. Antibiotic use in Hajj is common, with up to $58.5 \%$ of pilgrims having used these medications during the event [28]. Many antibiotics are prescribed empirically during Haji, especially in primary-care settings, with a tendency to prescribe broad-spectrum agents given a limited time to assess patients and to cover suspected infections. High prevalence of antibiotics use is however not unique to Hajj. One study found that in over half of the 44 countries investigated, more than $50 \%$ of patients were treated with antibiotics [29]. The latter study also reported that the percentage of patients treated with an injection ranged between 10 and $57 \%$ in most countries [29]. In our study, this percentage was $2.7 \%$, which is lower than reported from outpatients clinics in Hajj hospitals (6.5\%) [5], as well as the proposed optimal range 
for this indicator (13.4-24.1\%) [22, 27]. Beyond being uncomfortable for patients and more costly, excessive use of injections can result in a higher risk of bloodborne diseases [30].

For the final prescribing indicator determined in this study, we found that all of the prescribed drugs appeared on the essential drug list available in the PHCCs. This is at the higher end of the range reported from other countries (58-100\%), and similar to values from Hajj seasonal hospitals (100\%) and non-Hajj PHCCs in KSA (99.2\%) [5, $23,29]$. These results are not surprising given that during Hajj, physicians only prescribed medications from the list available in the PHCCs' pharmacy electronic system. As part of the Hajj health services readiness, all Hajj seasonal hospitals and PHCCs have a list of all medications available and stocked at each facility before they become operational. As such, all PHCCs also had a copy of essential drug list/formulary, which is the optimal value (100\%) for this facility-specific indicator [27, 31]. This is similar to what was reported from seasonal Hajj hospitals [5], but slightly higher than findings from non-Hajj PHCCs in other parts of the Kingdom (90\%) [32].

For patient-care indicators, we found that the percentage of medicines actually dispensed in our study was $92.7 \%$. This is comparable to what was reported from seasonal Hajj hospitals (90.0\%), non-Hajj PHCCs in KSA (99.6\%), and close to the optimal value of $100 \%$ $[5,27,32]$. In general, unavailability of medication is the main reason for lower values of this indicator [33]. However, given the way medications are provided to, and managed within, seasonal health facilities during Hajj, it is likely that other factors may explain the nonoptimal value of this indicator in our study. These include medication not dispensed for patients who have already been dispensed the same medications in previous visits to the same PHCCs or other healthcare facilities in the holy sites, medications dispensed but not entered into the PHCCs' pharmacy electronic system, or pilgrims simply not picking up their prescribed medications [5]. Given the retrospective design of the current study and the available data, we were unable to calculate the WHO indicator; average dispensing time for medications. However, we calculate a proxy indicator which is the average time between prescribing and dispensing of medications in the PHCCs. This value was $8 \mathrm{~min}(\mathrm{SD}=41.4)$, which is half of that reported from hospitals in the same locations (16.4 min; $\mathrm{SD}=119.8$ ) [5]. However, similar to the latter study, we found that most medications were dispensed within $10 \mathrm{~min}$ of being prescribed, with health facilities in Arafat being the slowest. This can be explained by the fact that these facilities have a much higher rate of encounters per working hours, given that they serve the entirety of the Hajj population for a single day [5].
The present study has some limitations. First, the study was conducted in 51 seasonal PHCCs in the holy sites and was limited to mainly the Hajj ritual days. Pilgrims attend 139 PHCCs in Makkah and in Medina throughout the 2-month Hajj season [2]. Therefore, our results may not reflect the pattern of disease and medication prescribing in all PHCCs throughout the Hajj season. However, our study included $55 \%$ of PHCCs in the holy sites [2], and our results are similar to those reported from studies of randomly selected holy sites PHCCs $[9,10]$. Therefore, our findings are an appropriate reflection of the situation in Hajj seasonal PHCCs. Second, pilgrims may acquire medication through various health facilities and private pharmacies available in Hajj, including their countries' medical missions, or use medication brought from home countries. Hence, our results reflect only part of the overall medication use and pattern among pilgrims during Hajj. Finally, based on the available data, only some of the WHO drug use indicators could be calculated.

In summary, we reported on the pattern of disease, caseload, and medication prescribing and dispensing at seasonal PHCCs during the 2019 Hajj mass gathering. Most patients were seen in Mina and post the day of Arafat. Respiratory diseases, particularly URIs, were the most common diagnoses, followed by musculoskeletal and skin diseases. The most prescribed classes of medications were analgesics, antibiotics, anti-inflammatory and antirheumatic products, and cough and cold preparations. Our results provide policymakers and Hajj stakeholders with the evidence base to optimize planning, resources allocation and delivery of healthcare services during Hajj. Some recommendations can be made. For example, healthcare resources, including staff and consumables, should be mobilized to diagnose and treat respiratory, musculoskeletal and skin diseases, and to prepare Mina PHCCs for the influx of patients post the day of Arafat. Ensuring accessibility to healthcare at pilgrims' camps, through the pilgrims' medical missions or dedicated healthcare officers, would reduce the load on PHCCs in the holy sites. Similarly, given the large burden of respiratory infections and the common use of antibiotics, introduction of point-of-care molecular diagnostics would ensure rapid diagnosis of these infections and identification of their causative agents, reducing unnecessary antibiotic prescribing. Our study is the first report of some of the WHO indicators for drug use in Hajj PHCCs. Given the unique context of Hajj and its population, objective norms for the indicators calculated in this study do not exist, and our values are not comparable to optimal values reported for non-mass gatherings settings [22, $27,31]$. Therefore, indicators reported in this study, along with findings from seasonal hospitals in Hajj [5], can be used to guide standards for medication prescribing and 
use during Hajj and other mass gatherings, and develop optimal values for these indicators in such contexts.

\section{Acknowledgements}

Not applicable.

\section{Authors' contributions}

SY: Conceptualization; Methodology; Formal analysis; Supervision; Validation; Writing original draft; Review \& editing of manuscript. YY: Investigation; Methodology; Project administration; Resources; Review \& editing of manuscript. AM: Investigation; Data curation; Review \& editing of manuscript. YA: Investigation; Data curation; Review \& editing of manuscript. AK: Supervision; Validation; Review \& editing of manuscript. All authors read and approved the final version of the manuscript.

\section{Authors' information}

Not applicable.

\section{Funding}

None to declare.

\section{Availability of data and materials}

The datasets used and analysed during the current study are available from the corresponding author on reasonable request.

\section{Declarations}

\section{Ethics approval and consent to participate}

Retrieved data were de-identified for confidentiality and to protect the personal health information of patients. The study was approved by the King Fahad Medical City Ethics Committee and the Institutional Review Board (IRB log \#:19-394E), a national approving committee and conducted in accordance with the Ethics Committee's guidelines. King Fahad Medical City Ethics Committee and the Institutional Review Board approved informed consent waiver for this observational study of deidentified data.

\section{Consent for publication}

Not applicable.

\section{Competing interests}

No conflicts of interest to declare.

\section{Author details}

${ }^{1}$ The Global Centre for Mass Gatherings Medicine, Ministry of Health, Riyadh, Saudi Arabia. ${ }^{2}$ Department of Emergency Medicine, College of Medicine, King Saud University, Riyadh, Saudi Arabia.

Received: 1 September 2021 Accepted: 13 January 2022

Published online: 03 February 2022

\section{References}

1. Tagliacozzo E, Toorawa SM. The Hajj : pilgrimage in Islam. New York: Cambridge University Press; 2016

2. Saudi Ministry of Health: 2018 statistical yearbook. 2018.

3. Aldossari M, Aljoudi A, Celentano D. Health issues in the hajj pilgrimage: a literature review. East Mediterr Health J. 2019:25(10):744-53.

4. Khan ID, Khan SA, Asima B, Hussaini SB, Zakiuddin M, Faisal FA. Morbidity and mortality amongst Indian Hajj pilgrims: a 3-year experience of Indian hajj medical mission in mass-gathering medicine. J Infect Public Health. 2018;11(2):165-70.

5. Yezli S, Zaraa S, Yassin Y, Mushi A, Stergachis A, Khan A. Medication utilization pattern among outpatients during the Hajj mass gathering. Saudi Pharm J. 2020:28(9):1122-8.

6. Al-Ghamdi SA, Akbar HO, Qari YA, Fathaldin OA, Al-Rashed RS. Pattern of admission to hospitals during muslim pilgrimage (Hajj). Saudi Med J. 2003;24(10):1073-6
7. Madani TA, Ghabrah TM, Al-Hedaithy MA, Alhazmi MA, Alazraqi TA, Albarrak $A M$, et al. Causes of hospitalization of pilgrims in the Hajj season of the Islamic year 1423 (2003). Ann Saudi Med. 2006;26(5):346-51.

8. Khamis NK. Epidemiological pattern of diseases and risk behaviors of pilgrims attending mina hospitals, Hajj 1427 h (2007 g). J Egypt Public Health Assoc. 2008;83(1-2):15-33.

9. Alzahrani AG, Choudhry AJ, Al Mazroa MA, Turkistani AH, Nouman GS, Memish ZA. Pattern of diseases among visitors to Mina health centers during the Hajj season, 1429 H (2008 G). J Infect Public Health. 2012;5(1):22-34.

10. El-Bushra HE, Abodahish AA. Utilization of primary health care services during Hajj. Saudi Med J. 1999;20(12):931-8.

11. World Health Organization. How to investigate drug use in health facilities: selected drug use indicators. Geneva: World Health Organization; 1993.

12. Masnoon N, Shakib S, Kalisch-Ellett L, Caughey GE. What is polypharmacy? A systematic review of definitions. BMC Geriatr. 2017;17(1):230.

13. Shakir HA, Gazzaz ZJ, Dhaffar KO, Shahbaz J. Outpatient services during (1423h) Hajj season. Sultan Qaboos Univ Med J. 2006;6(1):47-50.

14. Bakhsh AR, Sindy Al, Baljoon MJ, Dhafar KO, Gazzaz ZJ, Baig M, et al. Diseases pattern among patients attending holy mosque (haram) medical centers during Hajj 1434 (2013). Saudi Med J. 2015;36(8):962-6.

15. Alotaibi HM, Kabbash I. Factors affecting primary health care services utilization by Hajjis, 1430 H. Saudi Epidemiol Bull. 2010;17(1):4-5.

16. Hoang VT, Gautret P. Infectious diseases and mass gatherings. Curr Infect Dis Rep. 2018;20(11):44.

17. Fatani Ml, Al-Afif KA, Hussain H. Pattern of skin diseases among pilgrims during Hajj season in Makkah, Saudi Arabia. Int J Dermatol. 2000;39(7):493-6.

18. Alshehri MA, Alzaidi J, Alasmari S, Alfaqeh A, Arif M, Alotaiby SF, et al. The prevalence and factors associated with musculoskeletal pain among pilgrims during the Hajj. J Pain Res. 2021;14:369-80.

19. Yezli S, Mushi A, Almuzaini Y, Balkhi B, Yassin Y, Khan A. Prevalence of diabetes and hypertension among Hajj pilgrims: a systematic review. Int J Environ Res Public Health. 2021;18(3):1155.

20. Alqahtani AS, Althimiri NA, BinDhim NF. Saudi Hajj pilgrims' preparation and uptake of health preventive measures during Hajj 2017. J Infect Public Health. 2019;12(6):772-6.

21. BaDawood AO, Bossei AA, AISabhani MF, AIAhmari SM, Shata MT, Hamam AF. The burden on EDs during Hajj due to pilgrim noncompliance with treatment for chronic conditions. SJEMed. 2020;1(2):103-9.

22. Isah AO, Laing R, Quick J, Mabadeje AFB, Santoso B, Hogerzeil H, et al. The development of reference values for the WHO health facility core prescribing indicators. West Afr J Pharmacol Drug Res. 2001;18(1):6-11.

23. El Mahalli AA. WHO/INRUD drug prescribing indicators at primary health care centres in eastern province, Saudi Arabia. East Mediterr Health J. 2012;18(11):1091-6.

24. Hovstadius B, Petersson G. The impact of increasing polypharmacy on prescribed drug expenditure-a register-based study in Sweden 20052009. Health Policy. 2013;109(2):166-74.

25. Reason B, Terner M, Moses McKeag A, Tipper B, Webster G. The impact of polypharmacy on the health of Canadian seniors. Fam Pract. 2012:29(4):427-32.

26. Herr M, Robine JM, Pinot J, Arvieu JJ, Ankri J. Polypharmacy and frailty: prevalence, relationship, and impact on mortality in a French sample of 2350 old people. Pharmacoepidemiol Drug Saf. 2015;24(6):637-46.

27. Akl OA, El Mahalli AA, Elkahky AA, Salem AM. WHO/INRUD drug use indicators at primary healthcare centers in Alexandria, Egypt. J Taibah Univ Med Sci. 2014;9(1):54-64.

28. Hoang VT, Nguyen TT, Belhouchat K, Meftah M, Sow D, Benkouiten $S$, et al. Antibiotic use for respiratory infections among Hajj pilgrims: a cohort survey and review of the literature. Travel Med Infect Dis. 2019;30:39-45

29. Holloway KA, Henry D. WHO essential medicines policies and use in developing and transitional countries: an analysis of reported policy implementation and medicines use surveys. PLoS Med. 2014;11(9):e1001724

30. World Health Organization: Promoting rational use of medicines: core components - WHO policy perspectives on medicines. Geneva: World Health Organization; 2002. 
31. Atif M, Sarwar MR, Azeem M, Naz M, Amir S, Nazir K. Assessment of core drug use indicators using WHO/INRUD methodology at primary healthcare centers in Bahawalpur, Pakistan. BMC Health Serv Res. 2016;16(1):684.

32. El Mahalli AA, AkI OA, Al-Dawood SF, Al-Nehab AA, Al-Kubaish HA, Al-Saeed S, et al. WHO/INRUD patient care and facility-specific drug use indicators at primary health care centres in eastern province, Saudi Arabia. East Mediterr Health J. 2012;18(11):1086-90.

33. Atif M, Sarwar MR, Azeem M, Umer D, Rauf A, Rasool A, et al. Assessment of WHO/INRUD core drug use indicators in two tertiary care hospitals of Bahawalpur, Punjab, Pakistan. J Pharm Policy Pract. 2016;9:27.

\section{Publisher's Note}

Springer Nature remains neutral with regard to jurisdictional claims in published maps and institutional affiliations.

- fast, convenient online submission

- thorough peer review by experienced researchers in your field

- rapid publication on acceptance

- support for research data, including large and complex data types

- gold Open Access which fosters wider collaboration and increased citations

- maximum visibility for your research: over $100 \mathrm{M}$ website views per year

At BMC, research is always in progress.

Learn more biomedcentral.com/submissions 